\title{
Acute Myocardial Infarction due to Multiple Thrombosis without Cardiogenic Shock
}

\author{
Yurdaer Dönmez $^{\mathrm{a}} \quad$ Armağan Acele $^{\mathrm{a}} \quad$ Zikret Köse $^{\mathrm{b}}$ \\ a Department of Cardiology, Adana City Research and Training Hospital, University of Health Sciences,

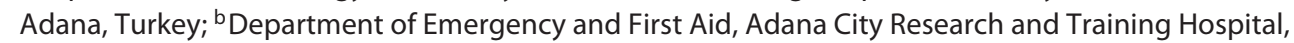 \\ University of Health Sciences, Adana, Turkey
}

\section{Significance of the Study}

- We report a case of simultaneous anterior and inferior myocardial infarction without cardiogenic shock. The patient's outcome was very good with percutaneous coronary interventional therapy. We suggest that when there is a multiple ST segment elevation in electrocardiography, clinicians should be aware of simultaneous coronary occlusions.

\section{Keywords}

Acute myocardial infarction · Multiple thrombosis .

Cardiogenic shock

\begin{abstract}
Objective: Acute thrombotic occlusion of $>1$ major coronary arteries is very rare (2.5\%). Herein, we report a patient with simultaneous anterior and inferior myocardial infarction without cardiogenic shock. Clinical Presentation and Intervention: A 43-year-old woman was admitted with severe chest pain. Electrocardiography showed ST segment elevation in anterior and inferior derivations. There was no severe hypotension. Urgent coronary angiography showed that there were thrombotic occlusions in both left anterior descending artery and right coronary artery. Both lesions were successfully treated with coronary stenting. Conclusion: If
\end{abstract}

\section{KARGER}

E-Mail karger@karger.com www.karger.com/mpp (c) 2018 The Author(s) Published by S. Karger AG, Basel Karger
Open access

This is an Open Access article licensed under the Creative Commons Attribution-NonCommercial-4.0 International License (CC BY-NC) (http://www.karger.com/Services/OpenAccessLicense), applicable to the online version of the article only. Usage and distribution for commercial purposes requires written permission. there is multiple ST segment elevation on presentation electrocardiography, clinicians should be aware of possible simultaneous coronary occlusions.

(c) 2018 The Author(s)

Published by S. Karger AG, Basel

\section{Introduction}

Acute ST segment elevation myocardial infarction (STEMI) is caused by occlusion of major epicardial coronary arteries (ECAs). Acute multiple STEMI (AMSTEMI) due to thrombotic occlusion of $>1$ major ECAs can be seen very rarely (2.5\%) in STEMI-suffering patients. This is one of the most severe clinical situations a patient can suffer. Approximately a third of the patients present with cardiogenic shock and nearly a fourth of the patients 


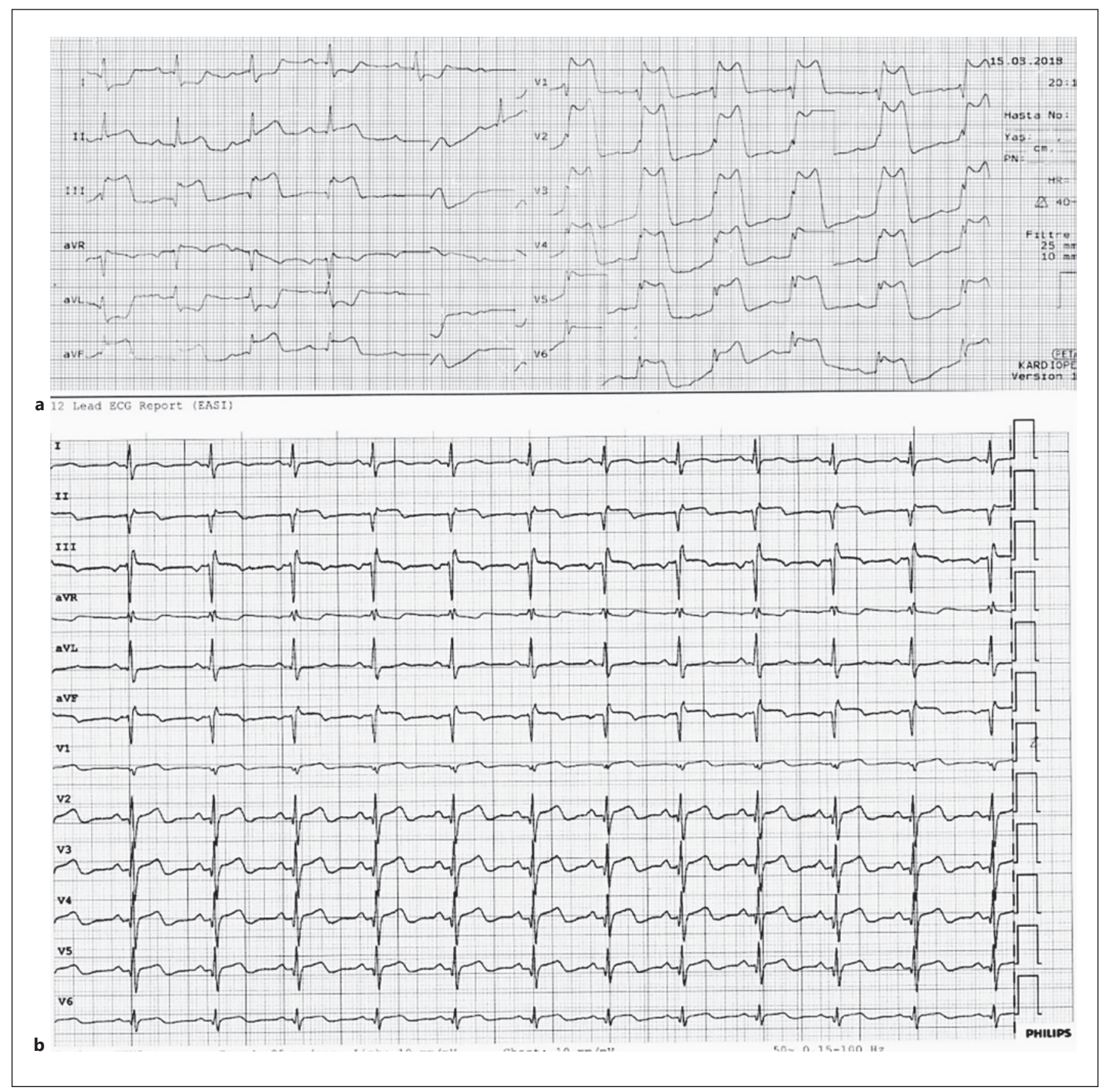

Fig. 1. a 12-Lead electrocardiography at admission. b ST segment resolution after primary PCI.

have life-threatening ventricular arrhythmias [1-3]. Herein, we report the case of a 43-year-old woman suffering from simultaneous anterior and inferior myocardial infarctions due to total thrombotic occlusion in both left anterior descending artery (LAD) and right coronary artery (RCA).

\section{Case Report}

A 43-year-old woman was admitted to our emergency department with a severe anginal chest pain which started an hour earlier. She had no known history of coronary artery disease. Her risk factors were hypertension, diabetes mellitus, and smoking (1 package/day for 16 years). There was no hemodynamic instability at 

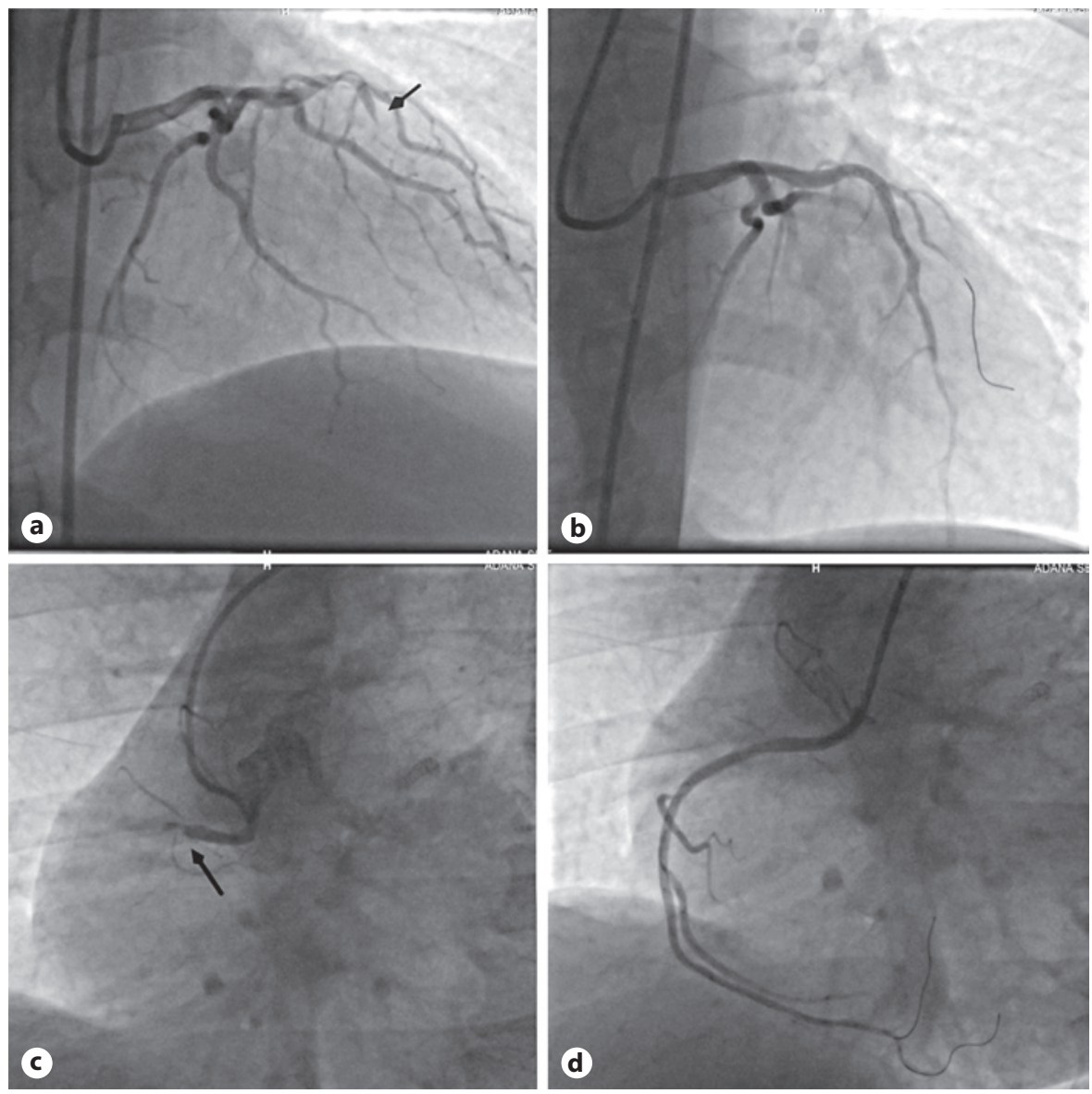

Fig. 2. a Total occlusion in the midportion of the LAD. b TIMI 3 flow in the LAD. c Total occlusion in the proximal segment of RCA. d TIMI 3 flow in RCA. coronary care unit. Metoprolol $50 \mathrm{mg}$ daily, ramipril $5 \mathrm{mg}$ daily, and rosuvastatin $20 \mathrm{mg}$ daily were given additionally. She was totally symptom free, and no complications occurred throughout the hospitalization. Transthoracic echocardiography showed no wall motion abnormalities at all. There was left ventricular hypertrophy secondary to hypertension, and the ejection fraction was $58 \%$. She was discharged on the 4th day of admission on acetylsalicylic acid (100 mg daily), ticagrelor $90 \mathrm{mg}$ (twice a day), metoprolol (50 mg daily), ramipril (5 $\mathrm{mg}$ daily), and rosuvastatin (20 $\mathrm{mg}$ daily).

\section{Discussion}

We have presented a young patient with simultaneous anterior and inferior acute myocardial infarction originating from thrombotic LAD and RCA occlusions. The primary percutaneous coronary intervention resulted in the excellent outcome.

AMSTEMI is an extreme clinical condition on which there is limited information in the literature; most of them are case reports. In one case series, its frequency was reported as $2.5 \%$ [3]. The main pathophysiological mecha- 
nism is thrombotic occlusion due to atherosclerotic plaques in acute myocardial infarction. But, simultaneous multi-vessel thrombosis can be secondary to the following causes: coronary vasospasm, vasoactive drug abuse, increased thrombotic conditions, rheumatoid diseases, adenosine receptor agonist-induced complications [4-6]. Some authors reported that there was a wrapped LAD or RCA in their patients [7, 8]. Chen et al. [9] described an unusual coronary anatomy which led to AMSTEMI. Sometimes, tumor-associated thrombotic thrombocytopenic purpura might be the reason for acute myocardial infarction [10]. If the patient's coronary angiogram has no gross atherosclerotic lesions, then the clinicians must specifically search for the secondary thrombosis reasons mentioned above. Our patient had classic coronary artery disease risk factors. Initial transthoracic echocardiography seemed normal except for the left ventricular hypertrophy. Thus, we did not screen the patient for a paradoxical etiology for embolism such as patent foramen ovale or atrial septal defect by transesophageal echocardiography. However, this kind of evaluation might be necessary to rule out such etiologic reasons in the follow-up period. There was no history of drug abuse in our patient. She was not using oral contraceptive drugs. Plasma levels of C-reactive protein, protein $\mathrm{C}$ and $\mathrm{S}$, fibrinogen, antithrombin III, and antiphospholipid antibody were normal. LAD and RCA lesions of our patient were highly atherosclerotic. Thus, we believe that increased atherosclerosis plus thrombotic process is the main etiology in our patient.

Literature suggests that the frequency of multi-vessel coronary thrombosis is very low, but complex plaques viewed in the course of STEMI has been estimated to be
40-65\%. Autopsy reports of sudden-death cases were demonstrated in up to $50 \%$ of multiple thrombosis in coronary arteries [4]. Why do not many patients with multiple vulnerable plaques suffer from AMSTEMI? Further detailed studies should address this clinical situation.

As the left ventricle is most often at risk in AMSTEMI, most patients present with serious conditions. Pollak et al. [3] reported 36\% cardiogenic shock and 23\% ventricular arrhythmias in their case series. Likewise, in a case review, Mahmoud et al. [4] reported $41 \%$ cardiogenic shock and $25 \%$ ventricular arrhythmias. Our patient had total occlusions in the LAD and RCA, and the remaining coronary flow was supplied by the left circumflex artery. She did not have cardiogenic shock and severe ventricular arrhythmias from admission until she was discharged.

Previous studies reported different combinations of ST segment elevation. Our case had ST segment elevation in the anterior and inferior locations. This finding was reported in about $20 \%$ of patients $[3,4]$. The majority of coronary angiograms of AMSTEMI patients revealed that there were about $50 \%$ simultaneous LAD and RCA occlusions. Our patient had these occlusions too.

\section{Conclusion}

Simultaneous multi-vessel coronary thrombotic occlusion is an extremely rare clinical condition. Most of the patients cannot be admitted to a hospital, and patients who are admitted suffer from serious clinical outcomes of multiple myocardial infarctions. Urgent invasive treatment should be given to all eligible patients.

\section{References}

1 Kanei Y, Janardhanan R, Fox JT, Gowda RM. Multivessel coronary artery thrombosis. J Invasive Cardiol. 2009 Feb;21(2):66-8.

2 Al Suwaidi J, Al-Qahtani A. Multiple coronary artery thrombosis in a 41-year-old male patient presenting with ST-segment elevation myocardial infarction. J Invasive Cardiol. 2012 Mar;24(3):E43-6.

3 Pollak PM, Parikh SV, Kizilgul M, Keeley EC. Multiple culprit arteries in patients with ST segment elevation myocardial infarction referred for primary percutaneous coronary intervention. Am J Cardiol. 2009 Sep;104(5): $619-23$.
4 Mahmoud A, Saad M, Elgendy IY. Simultaneous multi-vessel coronary thrombosis in patients with ST-elevation myocardial infarction: a systematic review. Cardiovasc Revasc Med. 2015 Apr-May;16(3):163-6.

5 Kalayci A, Arslan E, Bakar SM, Guneri M, Dizman R, Kivanc E, et al. Simultaneous thrombosis of multiple coronary arteries in a patient with rheumatoid arthritis. J Cardiovasc Thorac Res. 2016;8(2):86-7.

6 Hsi DH, Marreddy R, Moshiyakhov M, Luft $\mathrm{U}$. Regadenoson induced acute ST-segment elevation myocardial infarction and multivessel coronary thrombosis. J Nucl Cardiol. 2013 Jun;20(3):481-4.

7 Akdemir R, Gündüz H, Özhan H, et al. Simultaneous Anterior and Inferior Myocardial Infarction Due To Occlusion of the Left Anterior Descending Coronary Artery. Turk J Med Sci. 2004;34:121-6.
8 Shan P, Li S, Huang Z, Huang W. A case of simultaneous anterior and inferior ST-segment elevation myocardial infarction due to isolated occlusion of a wrapped right posterior descending artery. J Electrocardiol. 2013 Jan-Feb;46(1):13-5.

9 Chen IC, Chao TH, Tsai LM. Simultaneous anterior and inferior wall myocardial infarction in a patient with unusual coronary anatomy. Acta Cardiol Sin. 2010;26:119-22.

10 Wang J, Cai X, Cheng X, Song P, Jiang S, Gong J. Acute myocardial infarction caused by tumor-associated thrombotic thrombocytopenic purpura: case report. Med Princ Pract. 2014;23(3):289-91. 